\title{
The importance of using mannequin-training models in first aid learning: Case of avulsed tooth
}

\author{
Eva Dolenc ${ }^{1 *}$, Damjan Slabe ${ }^{2}$ \\ ${ }^{1}$ University of Ljubljana, Faculty of Health Sciences, Zdravstvena pot 5, 1000 Ljubljana, Slovenia \\ ${ }^{2}$ University of Ljubljana, Faculty of Health Sciences, Zdravstvena pot 5, 1000 Ljubljana, Slovenia
}

\begin{abstract}
The avulsion of permanent teeth is one of the most serious dental injuries, and correct emergency management is very important for the prognosis. Students of health care must be able to manage such emergency cases properly. Practical skill training on models can significantly improve the performance of students prior to the transition to a real patient. In Slovenia at the Faculty of Health Sciences at the University of Ljubljana, students get knowledge in the field of first aid, including tooth damage. The purpose is to evaluate the effectiveness of first aid training in case of teeth avulsion based on the mannequin-training model. Data collection took place in the context of experimental research methods. A group of students, who practice with the help of the mannequin-training model is better prepared to give first aid in case of tooth avulsion if the accident really happens, compared to a group that was studying without the model.
\end{abstract}

\section{Introduction}

Avulsion of permanent teeth is one of the most serious dental injuries, and a prompt and correct emergency management is very important for the prognosis [1,2]. Avulsion is the condition where the tooth is completely displaced out of its socket [3]. It occurs in $1 \%-16$ $\%$ of all dental injuries [4]. In Brazil, studies reveal a prevalence of trauma to the permanent dentition, ranging from $10.6 \%$ to $58.6 \%$ among 12 year schoolchildren [5]. Among the different types of dental trauma, avulsion results in the greatest functional and aesthetic impairment due to its worse prognosis [6].

The management of an avulsed tooth depends on whether it is a primary tooth or a permanent one. In the case of a primary tooth, a replant is not recommended [3]. In the case of a permanent tooth avulsion, the emergency management should be as follows: The tooth is picked from the crown and not from the root, if the tooth is dirty, it must be washed under cold running water before repositioning it, and when the tooth is repositioned, the patient can bite on a handkerchief to hold it in place, if repositioning is not possible, the tooth must be stored in a physiological media such as milk, saliva, or saline. Storage in water must be avoided. A dental clinic must be visited immediately. A dental trauma could be

\footnotetext{
${ }^{*}$ Corresponding author: eva.dolenc@zf.uni-lj.si
} 
considered as an emergency, and an immediate intervention is needed, so it should be taught early as a first aid measure [1]. A prognosis for a replanted tooth very much depends on time that has passed from the time of avulsion to replantation. Time from avulsion to replantation should be as short as possible. Immediate replantation after a brief washing of the tooth under the running water or in a physiological solution is the best therapy for an avulsed tooth. Namely, the tooth dries quickly in the air, since its cells begin to lose vitality very quickly. With the prolongation of time when the tooth is exposed out of the socket, the probability of complications increases. After one hour, the amount of live cells is too small to enable the healing of alveolar membrane after the replantation of tooth [7].

In order to increase the public awareness by, for example, mass media campaigns, healthcare professionals, guardians and teachers should receive information on how to proceed in the case of these severe unexpected injuries [1,5]. Also, instructions may be given by telephone to people at the emergency site. Immediate replantation is the best treatment at the site of accident [1]. Therefore, dentists should always be prepared to give an appropriate advice to public about first aid in case of avulsed teeth [1]. Actually, all medical stuff personnel need to receive simple instructions about the management of dental trauma [8]. Also, stomatology students or other students of health care must be able to properly manage such emergency cases [3]. In their study Azmi and Awooda [3] concluded that most of the undergraduate dental students are not qualified enough to manage an avulsion of teeth, and some have very week and insufficient knowledge about the emergency management in such situations. The majority of physicians $(83 \%)$ did not receive information on what to do if a tooth is knocked-out, and $97 \%$ did not have any dental health education course during their study. On the other hand, $93 \%$ of dentists received information on what to do if a tooth is knocked-out [8].

First aid education programmes, public health campaigns and formal first aid training are recommended in order to improve prevention, recognition and management of different injuries and illnesses [9]. A step from theory to application on patients is huge [10]. The traditional teaching methods are not always the most appropriate and effective [11]. The European Resuscitation Council guidelines 2015 [9] support the use of simulations in the teaching of basic resuscitation procedures. They are also mentioned in the International guidelines for first aid and resuscitation as an effective method of teaching [12]. In the field of dental medicine, there are numerous studies that emphasize the importance of innovative learning approaches, also the use of mannequin training models [10, 13, 14, 15]. However, the focus of the training should be on the actual real situation [10]. In the case of avulsion of a tooth this is not possible.

In Slovenia at the Faculty of Health Sciences at the University of Ljubljana students get knowledge in the field of first aid, including tooth damage. Knowledge is adopted in the framework of the course Fundamentals of clinical medicine and first aid in the first and second year of study. It is part of the curriculum of undergraduate studies for eight courses at the Faculty of Health Sciences: midwifery, occupational therapy, physiotherapy, laboratory dental prosthetics, orthotics and prosthetics, radiological technology, sanitary engineering and nursing.

The purpose of our research is to evaluate the effectiveness of first aid training in case of teeth avulsion, based on the mannequin-training model. The aim is to determine whether the use of mannequin-training model improves the provided first aid, and how the participants of training assess the usefulness of these models in preparation for real situations. Two hypothesis were tested:

- students who practised on the mannequin-training model are more confident about their readiness for real situation in case of tooth avulsion,

- students who practised on the mannequin-training model have better knowledge of first aid measures in real situation in case of tooth avulsion. 


\section{Method}

Data collection took place in the context of experimental research methods according to the preceding literature review, with the use of an anonymous questionnaire, video, mannequin-training model (Figure 1) and evaluation assessment sheet. The research was conducted in the period from February to March 2019. The subject of research were students of the Faculty of Health Sciences at University of Ljubljana. Participation was voluntary and anonymous and didn't have any impact on the evaluation of the study obligations. The sample included 41 students. Students were randomly assigned to experimental $(\mathrm{n}=21)$ or control $(\mathrm{n}=20)$ group. All students (from both groups) participated at a first-aid lecture in the framework of the course Fundamentals of clinical medicine and first aid. They had theoretical lectures on first-aid measures in case of tooth damage. Before the practical test, the members of experimental group also practised with mannequin-training models, but the members of control group did not, so they only listened to theoretical lectures. After that, data on first aid knowledge of tooth injury have been collected with a practical test in a simulated case of tooth damage. In order to perform the experiment, we created a mannequin-training model of the face with a knocked up tooth (Figure 1), and made a video showing the tooth injury accident. Participants in the survey were asked to perform first aid procedures after watching the video, with a first aid kit available. The procedures obtained were evaluated using a developed evaluation assessment sheet.

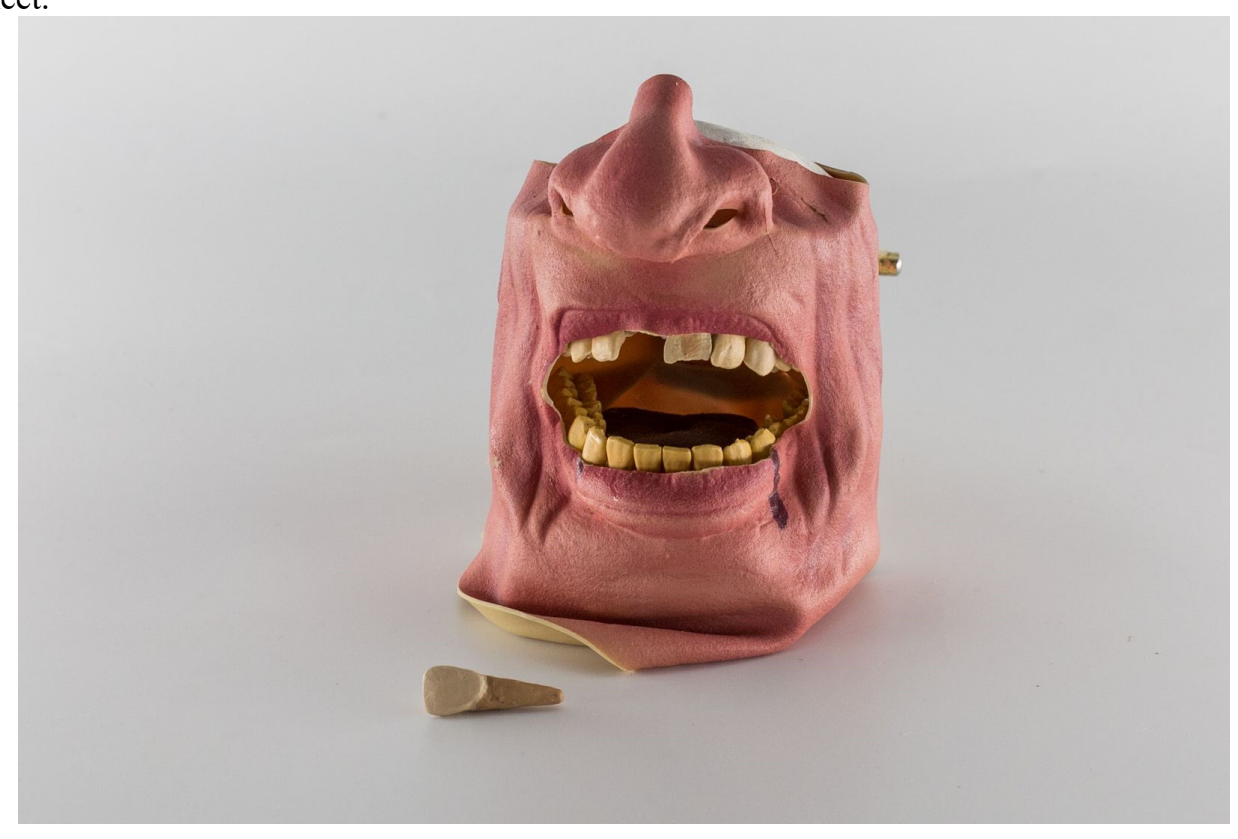

Figure 1: Mannequin-training model with avulsed tooth (Photo: Pirc M.)

Differences between the experimental groups were statistically analysed with independent samples t-test and Fisher's exact test. We used the statistical software package SPSS version 25 for Windows. All levels of significance were set at $p<0.05$. The results of the study were compared with the results of other studies in Slovenia and abroad. 


\section{Results}

41 students were included in the sample, out of these $(76 \%)$ were female and 19 years old $(\bar{x}=19.5)$. All of them were first year students at the Faculty of Health Sciences, direction Radiology and Healthcare.

Students from the experimental group have typically much better evaluated their knowledge that could be potentially used if they actually had to help an injured person with a konked-out tooth in comparison to students from the control group (Table 1).

Table 1: Comparison of average (self) grades among student groups.

\begin{tabular}{|c|c|c|c|}
\hline & $\begin{array}{c}\text { experimental }(\overline{\mathrm{x}} \\
\text { in } \sigma)\end{array}$ & $\begin{array}{c}\text { control } \\
(\overline{\mathrm{x}} \text { in } \sigma)\end{array}$ & p-value \\
\hline Self-assessed knowledge about first aid & $4,1(0,3)$ & $3,9(0,6)$ & 0,173 \\
\hline $\begin{array}{c}\text { Satisfaction with the information students get during } \\
\text { lectures about first aid measures in the case of tooth } \\
\text { avulsion }\end{array}$ & $4,81(0,5)$ & $4,5(0,6)$ & 0,086 \\
\hline $\begin{array}{c}\text { Self-assessed knowledge about first aid measures in } \\
\text { case of tooth avulsion as preparation for using it in } \\
\text { real situation. }\end{array}$ & $4,43(0,6)$ & $3,75(0,6)$ & $0,001^{*}$ \\
\hline
\end{tabular}

Legend: * there is a statistically characteristic difference between groups of students $(p<0,05)$

The biggest differences between these two groups in the first aid procedure where shown in the decision whether to reinplant the avulsed tooth, or store it in an appropriate medium. (Table 2)

Table 2 : The comparison of measures taken in the first aid procedure in the case of an avulsed tooth between two groups of students.

\begin{tabular}{|c|c|c|c|}
\hline & experimental & control & p-value \\
\hline Use of gloves & $43 \%$ & $35 \%$ & 0.751 \\
\hline Stop bleeding & $43 \%$ & $60 \%$ & 0.354 \\
\hline Touch the root & $10 \% *$ & $55 \%$ & $0.003^{*}$ \\
\hline Tooth washing & $86 \% *$ & $20 \%$ & $0.000^{*}$ \\
\hline Reduction of the tooth in the appropriate \\
medium & $76 \% *$ & $20 \%$ & $0,000^{*}$ \\
\hline Transport to the dentist & $24 \% *$ & $65 \%$ & $0.012^{*}$ \\
\hline
\end{tabular}

Legend: *there is a statistically characteristic difference between groups of students $(p<0,05)$

Students of both groups asses milk as the most adequate medium for storing an avulsed tooth (Table 3). 5\% of students from both groups were familiar with dishes for storing teeth. 
Table 3: The comparison of average marks given to the adequacy of media (1-an inadequate medium, 5-a very adequate medium) for storing an avulsed tooth, the comparison between two groups of students.

\begin{tabular}{|c|c|c|}
\hline Medium for storing an avulsed tooth & experimental $(\overline{\mathrm{x}}$ in $\sigma)$ & control $(\overline{\mathrm{x}}$ in $\sigma)$ \\
\hline sterile gaze & $2,43(1,4)$ & $3,60(1,1)$ \\
\hline airtight sealed container & $2,10(1)$ & $2,50(1,7)$ \\
\hline water & $2,86(1,4)$ & $2,70(1,2)$ \\
\hline saline & $4,24(0,6)$ & $2,95(1,3)$ \\
\hline saliva of the injured person & $4,71(0,5)$ & $4,05(1,4)$ \\
\hline alcohol & $1,05(0,2)$ & $1,00(0)$ \\
\hline juice & $1,05(0,2)$ & $4,45(0,9)$ \\
\hline milk & $4,9(0,3)$ & \\
\hline
\end{tabular}

\section{Discussion and conclusion}

The results show that students from the experimental group are more confident about their first aid knowledge in case of tooth avulsion. Abu-Dawoud et al. [8] found out that apart from dentists, other healthcare workers (physicians) had not received information on what to do if a tooth is knocked-out. As far as knowledge level is concerned, none of the physicians showed a high knowledge level, in sharp contrast to $78.5 \%$ of dentists who had high knowledge and none demonstrated low knowledge. They concluded that emergency dental treatment is sometimes required to be provided by a physician before any dental contact. In a related research, $46 \%$ of teachers and students of physical education had no knowledge on first-aid measures regarding tooth avulsion. Sending the patient with avulsed tooth to the dentist was the most often cited measure [5].

In our research the actual knowledge of experimental group is statistically significantly better in comparison to the control group. Nearly $90 \%$ of them cleaned avulsed tooth before they replanted it or placed it in the appropriate medium, while in the control group only $20 \%$ of the members did so. If the tooth is dirty, you should wash it briefly (10 s) under cold running water [1]. Besides that, more than $50 \%$ of the members of control group held the tooth's crown, which is not correct [1]. The largest differences between the two groups were in the application of the first aid measures: replantation or storage of the tooth in a medium. More than three quarters of the participants in the experimental group, and $20 \%$ of the participants in the control group replanted the tooth. Other participants stored the tooth in the appropriate medium (either milk or saliva of the injured person). Both measures are correct. Similar, $92 \%$ teachers and students of physical education judged themselves as incapable of performing an immediate replantation [5]. Francisco et al. [16] found out that only $13 \%$ of teachers would replant the tooth in the socket, and only $7 \%$ said that they would put the tooth in some liquid, and $58 \%$ would store it in a piece of paper, a cloth or a clean container. All of the students included in the research assessed milk or saliva of the injured person as the most appropriate medium, and in the experimental group also the physiological solution. It has been established that students were undecided about the adequacy of water as a medium for tooth storage, since the average mark is 2,5 (between 1-inadequate and 5-very adequate medium). Most of them 
were also not familiar with dishes for tooth storage, which is expected, since such dishes are not available in Slovenia.

The ideal replantation has a tooth out of the tooth socket for less than 5 minutes; therefore, it is necessary to make efforts to insert the tooth as quickly as possible after the injury [1]. If students do not learn such a measure by using mannequin-training model, they do not take this action in a simulated crash. In different fields of dentistry, g. g. tooth extractions, it has been shown that practical skill training on models can significantly improve the performance of students prior to the transition to real patient $[17,18]$. Local anesthesia training models are also a valuable didactic complement and have beneficial effects $[10,13,14]$. Students who have used a preclinical training model for practising local anesthesia considered it a useful preparation for their first injection in a human [14]. Research also suggests that nursing students want more simulations for learning their skills [19].

Our findings highlight the importance of practical learning exercises, using the mannequin-training models, for readiness to act in a real situation. Since Slovenian health and medicine students are obliged by law [20] to provide first aid, it is important that they are familiar with these procedures.

Our study has several limitations. Although experimental in design, a limitation of this study was the small sample size and evaluation of students at only one school.

Acknowledgements: Special thanks to Bernik Jan, student of Laboratory dental prosthetics, who made mannequin-training model with avulsed tooth used in the study.

\section{References}

1. L. Andersson, J.O. Andreasen, P. Day, G. Heithersay, M. Trope, A.J. Diangelis, DJ. Kenny, A. Sigurdsson, C. Bourguignon, M. T. Flores, M. L. Hicks, A. R. Lenzi, B. Malmgren, AJ.Moule, M.Tsukiboshi, International Association of Dental Traumatology . International Association of Dental Traumatology guidelines for the management of traumatic dental injuries : 2. Avulsion of Permanent Tooth, 28 (2): 88-96, (2012)

2. A. Al Asfour, L. Andersson, Q. Al-Jame. School teachers'knowledge of tooth avulsion and dental first aid before andafter receiving information about avulsed teeth and replanta-tion. Dent Traumatol, 24:43-9, (2008)

3. M. Azmi Azmir, E. Awooda Mohieldin. Knowledge of emergency management of avulsed tooth among undergraduate preclinical and clinical dental students : Questionnaire-based study. Journal of Dental Research and Review, 3 (4): 140-143, (2017)

4. Y. Fujita, Y. Shiono, K. Maki. Knowledge of emergency management of avulsed tooth among Japanese dental students. BMC Oral Health, 14:34, (2014)

5. K.O. Jorge, M.L. Ramos-Jorge, F.F. de Toledo, L.C. Alves, S.M. Paiva, P.M. Zarzar. Knowledge of teachers and students in physical education's faculties regarding first-aid measures for tooth avulsion and replantation. Dent Traumatol, 25(5):494-9, (2009)

6. S.R. Panzarini, D. Pedrini, D.A. Brandini, W.R. Poi, M.F. Santos, J.P. Correa et al. Physical education undergraduates and dental trauma knowledge. Dent Traumatol, 21:324-8, (2005)

7. J.O. Andreasen, F.M. Andreasen, L. Andersson. Textbook and Colour Atlas of Traumatic Injuries to the teeth. 4th ed. Oxford: Blackwell, 444-88, 669-715, 740-60, (2007) 
8. M. Abu-Dawoud, B. Al-Enezi, L. Andersson. Knowledge of emergency management of avulsed teeth among young physicians and dentists. Dent Traumatol, 23:348-55, (2007)

9. The European Resuscitation Council guidelines 2015. P. Gradišek, M. Grošelj Grenc, A. Strdin Košir et al., Smernice za oživljanje 2015 Evropskega reanimacijskega sveta. 1. izd. Ljubljana: Slovensko združenje za urgentno medicino. Accessed via: http://www.szum.si/media/uploads/files/ERC_2015_slo-1.pdf (2015)

10. Knipfer, C., Rohde, M., Oetter, N., Muench, T., Kesting, M. R., \& Stelzle, F. Local anaesthesia training for undergraduate students - how big is the step from model to man? BMC Medical Education, 18 (1), 308, (2018)

11. J. Lippmann, P. Livingston, M. Craike, Health Educ J, 70, 2 (2011)

12. International Federation of Red Cross and Red Crescent Societies. International first aid and resuscitation guidelines 2016. Geneva. Accessed via: http://www.ifrc.org/Global/Publications/Health/First-Aid-2016-Guidelines_EN.pdf (2016)

13. J.S. Lee, R. Graham, J.P. Bassiur, R.M. Lichtenthal. Evaluation of a Local Anesthesia Simulation Model with Dental Students as Novice Clinicians. J Dent Educ., 79 (12):1411-7, (2015)

14. H.S. Brand, J.A. Baart, N.E. Maas, I Bachet. Effect of a training model in local anesthesia teaching. J Dent Educ., 74 (8):876-9, (2010)

15. J.A. Buchanan. Use of simulation technology in dental education. $J$ Dent Educ., 65(11):1225-31, (2001)

16. S.S. Francisco, A de Jesus Soares, R. Dutra Murrer. Evaluation of elementary education teachers' knowledge on avulsion and tooth replantation. $R S B O, 12(1): 32-40,(2015)$

17. I. Marras, N. Nikolaidis, G. Mikrogeorgis, K. Lyroudia, I. Pitas. A virtual system for cavity preparation in endodontics. J Dent Educ., 72(4):494-502, (2008)

18. F. Stelzle, D. Farhoumand, F.W. Neukam, E. Nkenke. Implementation and validation of an extraction course using mannequin models for undergraduate dental students. Acta Odontol Scand., 69(2):80-87, 82011)

19. J. McCallum, Nurse Educ Today, 27, 8 (2007)

20. Health Care and Health Insurance Act (ZZVZZ-UPB3). Ur. 1. RS 72/2006, (2006). 